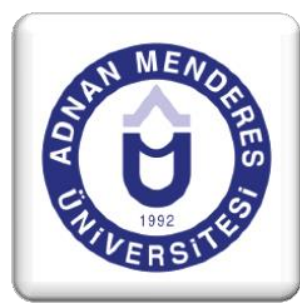

\title{
Eleştirel Medya Okuryazarlığı Kapsamında Çocuk Odaklı Haber ve Programlar Üzerine Bir Değerlendirme
}

\section{An Assessment on Child-Centered News and Programs within the Context of Critical Media Literacy}

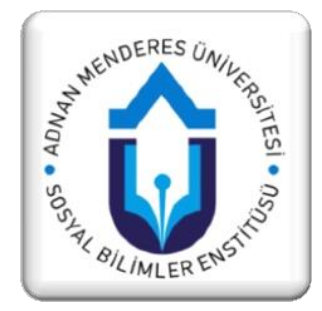

\author{
Hicabi ARSLAN ${ }^{1}$
}

\section{Özet}

Medya okuryazarlığının erken yaşlardan itibaren başlayarak hayat boyu geliştirilecek bir beceri olması, verilecek eğitimin de okul öncesinden başlayarak yetişkin eğitime uzanan bir sürece yayılmasını gerekli kılmaktadır. Bu nedenle eğitim kurumlarında, çocuklara, toplumla uyum içinde yaşaması ve toplumun ona sağladığı fırsatlardan yararlanabilmesi için gerekli temel davranışların kazandırıması hedeflenmektedir.

Uluslararası Gazeteciler Federasyonu'nun (FIJ) 2003 yılında yayınladığı "Medyada Çocuk Haklarını Tanıtmak" konulu bir atölye çalışmasında belirtildiğine göre; Dünya nüfusunun üçte ikisinden fazlasının çocuklardan oluştuğu, medyanın ancak yüzde beşinin çocuklara yönelik içerik taşıdığı bunun da büyük kısmının çocuk ruh ve beden sağlığını olumsuz etkilediği bilinmektedir.

Medya okuryazarlığı işte tam da burada devreye girerek bilinçli bir okuyucu kitlesini yetiştirmeyi amaçlamalı, medya programcıları, habercileri ve diğer kurumsal yapıları koordine ederek ruh ve beden sağlığı korunmuş, değerlerine bağlı bir neslin yetişmesine yardımcı olmalıdır.

Anahtar Kelimeler: Eleştirel Medya okuryazarlığı, Çocuk, Habercilik

\section{Abstract}

Media literacy takes a life long period beginning from the early ages. So, the media literacy education should start in the preschool period and outlasts the adult education.For this reason, educational institutions aim to bring in children to live in tune with the society and teach them the necessary behaviors in order to benefit of the opportunities that the society creates for them.

It is known that more than $2 / 3$ of the World consist of children wheras the $5 \%$ of media content are for them. Also most of this content have negative effects on children's both physical and mental health.

At this point, media literacy should be seen in the field and aim to raise conscious audience, media professionals, journalists and should coordinate other institutions in order to help to create a healthy and social-value oriented generation.

Key words: Critical media literacy, children, journal

\footnotetext{
${ }^{1}$ Assist. Prof. Dr., Department of the Art History, Adnan Menderes University, Aydin, Turkey
} 


\section{GiRiş}

Eğitim, İngilizce karşılığı olan "education", Latince "beslemek" anlamına gelen "educare" ve "dışarı çekmek", "bir şeye doğru götürmek " anlamına gelen "educere" sözcüklerinden türetilmiştir. Buradan hareketle eğitim, bireyin bilgiyle beslenmesi ve onda var olan yetilerin dışarı çekilmesi, ortaya çıkarılması ve geliştirilmesi olarak tanımlanabilir.

Eğitim sözcüğünün "eğmek" sözcüğüne dayalı olarak geliştirildiği ve bunun için insanların ve hatta hayvanların istenilen yönde biçimlendirilmelerini ima ettiği de ileri sürülmektedir (Duman, 2000: 13). Ağacı eğmek ve insanı ya da hayvanı eğitmek arasında bir ilişki kurulduğu için "ağaç yaş iken eğilir" atasözü ortaya çıkmıştır. Bu söz özünde çocukların küçük yaşta istenilen şekilde ve doğrultuda eğitilebileceğini anlatmaktadır.Buradan hareketle insanın, özellikle sosyal yaşama uyum sağlaması ve yaşamını en doğru en zararsız bir şekilde sürdürebilmesi için çocukluktan itibaren eğitim ve öğretime özendirilmesi zorunluluk halini almıştır.

Medya, artık yaşadığımız toplumun her alanında yer alıyor. Coğrafi sınırlar, teknolojik kısıtlamalar ya da radyo frekanslarının sınırlaması olmayan yeni uydu, kablo ve video sistemleri, uzaktan gösterimli ve film üretim sistemlerinin evrensel ve neredeyse anlık dağıtımını sağlamaktadır. Geriye kalan tek potansiyel bariyer, devlet düzenlemeleridir ve ancak bu düzenlemelerin yukarıdan (uydu) ve aşă̆ıdan gelen (video korsanlığı ve kaçakçılığı) bombardımanını nasıl durduracağı belirsizdir. Ancak bu belirsizliğe karşın tüm dünya, medyanın küreselleştiği şartlara kendini yenide uydurmaya çalışıyor. Eğitim ve öğrenme yeni bilgilenme biçimleri ve içeriği, medya ile olan ilişkisine yeni katkılar sağlıyor ve hatta okullar bu sürece müfredatlarında değişikliğe giderek destek veriyor (İnal, 2009: 13). Bir de medya ile birlikte sıkça anılan iletişim kavramı mevcuttur. İngilizce'deki "communication" kelimesinin karşılı̆ı olarak dilimize yerleşmiştir. Kavramın genel bir tanımını yapmak gerekirse; insanlar arasındaki her türlü bilgi, duygu ve düşünce alış-verişi, bilginin ortaklaşa kullanılması şeklinde özetlemek mümkündür (RTÜK, 2007: 5). Yapılan bütün araştırmalar ve bunlar üzerinde yapılan değerlendirmeler; görsel işitsel ve yazılı medya karşısında savunmasız bir alıcı durumunda bulunan çocukların ilköğretimden başlayarak medya karşısında bilinçlendirilmelerinin gerekliliğini ortaya koymaktadır. Böylelikle öğrenci; medya karşısında pasif bir alıcı olmak yerine, medyayı okuyabilecek, medyanın dilini çözebilecek bilinç düzeyine ulaşarak iletişim olgusunda aktif bir birey olarak yer alabilecektir.

Medya okuryazarlığının bireylerin medya tüketiminde daha eleştirel tüketiciler olmaları için bir takım düşünme becerilerine sahip olmaları gerektiği görüşüne dayandığı söylenebilir ki zaten medya okuryazarlığının tanımında da "yazılı ve yazılı olmayan büyük çeşitlilik gösteren yapılardaki (internet, televizyon v.b.) mesajlara ulaşma, bunları çözümleme, değerlendirme ve iletme yeteneği" ifadesi yer almaktadır. Gelişen teknoloji ile elektronik medya, kullandığı olağanüstü teknik ve kanallarla çocuklar ve yetişkinleri kendine çekmekte, maruz kalınan enformasyon bombardımanı altında özellikle çocuklar, kendilerine sunulan malzemeyi süzmeden olduğu gibi almaktadırlar (Avşar, 2014: 10).

Medyanın hem bireyler ve hem de çocuklar üzerindeki etkisi oldukça fazladır. Özellikle sosyal medyanın etkisi her geçen gün daha da artmakta, hayatın bir parçası olan her türlü şiddet ve olumsuzluğu da adeta meşrulaştırmakta ve tüketici konumunda olan çocuk yaştaki takipçileri etkisi altına alarak pasifize etmektedir. Medya tüketicilerini hangi yaşta olursa olsun, pasif tüketiciler ve aktif tüketiciler olarak ikiye ayırabiliriz. Pasif tüketiciler, izleyen, dinleyen, okuyan olarak sadece içeriği tüketenlerdir. Aktif tüketiciler ise telefon ve internet üzerinden oyun oynayarak veya sosyal medyada yer alarak iletişime katılımcı olarak iştirak ederler. Bize göre, medya tüketimini birey kendi bilinçli tercihi ile yapabiliyorsa ve istediği anda sonlandırabiliyorsa bağımlı olduğu söylenemez. Ancak işini, okulunu, uykusunu inmal edecek oranda teknoloji tüketimine ihtiyaç hissediyorsa burada bağımlııktan söz edebiliriz (Mora, 2014: 21). 
Çocuklar, medyada tüketim nesnesi olarak temsil edilmekte, teşhir edilmekte, damgalanmakta ya da dışlanmaktadır. Bunun nedenlerinden biri, medyanın erkek egemen bakış açısına sahip olmasıdır. Diğeri ise çocukların egemen ideolojinin onlara biçtiği role göre kategorize edilmesinden kaynaklanır. Medyada statükonun devamını sağlayacak değer yargılarını yeniden üreten egemen anlayış, haberlerde yer alacak toplumsal kavramları iyi/kötü üzerinden kurgular.

Kitle medyasında ya ünlü/popüler ya da marjinal olan yer alabildiğinden, sıradan bir çocuğun medyada yer alabilmesi, ya mağdur ya da suçlu olduğunda mümkün olabilmektedir. Bu durumun ortaya çıkmasında, medyanın ekonomi-politiği, profesyonel gazetecilik kodları, medya üretiminin hiyerarşik yapılanması ve kaynak kullanımında gücü/erki elinde bulunduranlara bağımlı kalması ve toplumsal cinsiyet faktörü etkili olmaktadır. Böylece medyada, gücü/erki elinde bulunduranlar daha fazla olumlu ve hiyerarşik sıralamada daha avantajlı konumda temsil edilirler (Mora, 2008: 73). Medyada, kamusal alanda üretilen bu temsiller ise toplumsal birer anlama dönüşerek gündelik yaşamda etkili olur. Bu nedenle medyada kimin nasıl temsil edildiği ve temsil olarak nelerin seçildiği ve nasıl aktarıldığı çok önemlidir (Mora, 2007: 69).

Sembolik görselliğin giderek egemen olmaya başladığı çağımızda bireylerin özellikle de çocukların ve gençlerin medyayı ve üretimlerini anlayabilmeleri için sembolleri ve kodları deşifre edebilme yeteneklerinin geliştirilmesi gerekmektedir. Bu noktada ebeveynlere de önemli görevler düşmektedir. Onlar da medya ortamı hakkında bilgilenmek ve iyi birer medya okuryazarı olmak zorundadırlar. Çünkü çocukların iyi birer medya okuryazarı olmalarının yolu, anne ve babalarına bağlıdır (RTÜK, 2007: 41). Öyle ki; günlük yaşantının birer parçası haline gelen bilgisayar, internet, cep telefonları, oyun konsolları, avuç içi veri bankası kayıtlayıcıları (ipod), bir başka deyişle tüm dijital teknolojiler yeni medya başlığı altında toplanmaktadır. Yeni medyanın geleneksel medyadan (gazete, radyo, televizyon, sinema) ayrılan temel özellikleri ise etkileşimli ve çoklu ortam biçemine sahip olması, çok sayıda bilgiyi aynı anda aktarabilmesi, farklı iletişim boyutlarının aynı anda gerçekleşmesini sağlamasıdır.

Medyanın sağladığı olanakların yanı sıra medyanın artan çeşitliliği ve bu çeşitliliğin her yaştaki bireyleri etkileme gücü, medya okuryazarlığı kavramını ortaya çıkarmıştır (Kurt ve Kürüm, 2010:2). Medya okuryazarlığı, görsel, işitsel medya ile çoklu medyanın büyük çeşitlilik gösteren formlardaki mesajlarına ulaşma, bunları çözümleme, değerlendirme ve iletme yeteneği olarak tanımlamaktadır. İzleyicinin medyayı bilinçli okumasını sağlayan medya okuryazarlığı, aynı zamanda insanın kendini özgürce ifade etmesi, bireyin toplumsal hayata daha aktif ve yapıcı olarak katılımını sağlaması, medyanın iyileştirilmesi ile ilgili hareketleri desteklemek için bilinç oluşturması açısından önem taşımaktadır.

Özellikle çocuk yaştaki medya tüketicilerinin ve daha ileriki aşamalarda gençlerin medyanın olumsuz baskısından nasıl etkilendiklerini irdelemek gerekli olmuştur. Elektronik kültürle yetişen çocukların ve gençlerin eğitim ve öğretim ortamında kendilerini yazılı ve sözlü ifade etme güçlüğü yaşadığı, dikkat dağınıklığı, yorgunluk, aşırı stres, mutsuzluk ve kendine güvenmeme gibi olumsuz bazı belirtiler, anne-babalar açısından bireysel ve devletler açısından ise kurumsal olarak bazı tedbirlerin acilen alınmasını ve otokontrolü gerekli kılmıştır.

\section{AMAÇ VE BULGULAR}

"Eleştirel Medya Okuryazarlığı Kapsamında Çocuk Odaklı Haber ve Programlar Üzerine Bir Değerlendirme" başlığı altındaki makalede öncelikle çocuk kavramı üzerinde durularak, medyanın hangi araçlarının çocukları ne şekilde etkilediği bu etkinin olumsuz yanları ele alınarak bu olumsuzluğun ne şekilde giderileceği üzerinde durulacaktır.

Çocuk ve çocukluk dönemine ilişkin yapılan tanımlar, evrensel bir takım kabullere rağmen genel olarak toplumların gelişmişlik düzeyleri, siyasi rejimleri ve süregelen kültürel kodlarıyla yakından ilgilidir. Tarihte görülen temel, egemen ve yaygın çocukluk imgeleri de sürekli olarak 
değişmiştir. İlk çağlarda hor görülen çocuk, aydınlanma ile fark edilmiş, değer görmeye başlamıştır (Aşar, 2014: 93).

Ulusal yasalarca daha erken yaşta ergin sayılma hariç, 18 yaşın altındaki her birey çocuk sayılır. Ergin yaşı kavramı hem ülkeler arasında hem de belirli bir ülkedeki hukuksal, siyasal, toplumsal ve diğer kurallara göre değişiklik göstermektedir.

Çağdaş toplumun çocuk paradigması, üç temel ilkeyi benimser:

1.Her doğan çocuğun hayata iyi bir başlangıç yapması,

2.Nitelikli eğitim alması,

3.Her çocuğun yeteneği doğrultusunda potansiyelinin geliştirilmesi, sosyalleşmesidir (Mora, 2007: 71).

Kimi tarihçilere göre çocukluk dediğimiz kategori, üzerine her türlü sözün repertuarıyla birlikte modern zamanlarda icat edilmiştir. Sanayi Devrimi'nin başlarında dahi çocuklar " biyolojik, psikolojik ve sosyal " olarak farklı değil büyüklerin minyatür örnekleri olarak kabul edilirlerdi. (Bostancı, 2012: Editörün Notu).

İnsanlık tarihine bugünkü anlamıyla yaklaşık olarak iki yüzyıl önce giren tüketim olgusu, gün geçtikçe modern toplumların hayatında daha önemli bir yer tutar olmuştur. İnsanların gündelik yaşamlarının temel belirleyicilerinden biri olan tüketim, artık ilk günkü anlamının sınırları içerisinde değildir. En önemli medya tüketicisi olarak kabul ettiğimiz çocuklar; küreselleşme ve bunun medya üzerindeki yansımaları olarak, değişen ve dönüşen ilişkiler nedeniyle aile yapısının, sosyal yapının bozulması, çiftlerin boşanmaları ve çocukların ebeveynlerini kaybetmeleri, toplumsallaşmanın temeli olan aile ortamından mahrum kalmaları nedenleriyle medya üzerinden toplumsallaşmaktadırlar.

Uluslararası Gazeteciler Federasyonu'nun (FIJ) “ Medyada Çocuk haklarını Tanımak " konulu bir atölye çalışmasında belirtildiğine göre; çocuklar dünya nüfusunun üçte ikisinden fazlasını oluşturdukları halde, medyanın kapsadığı konuların yüzde beşinden azı çocuklarla ilgili. Medya çocukları haber konusu yaptığında ise "çocuk fuhuşu, organ kaçakçılığı, cinsel istismar, eğitim ve sağıık hizmetlerinden mahrum bırakılmaları, çocuk emeği sömürüsü, sokak çocukları vb." başıkları öne çıkarıyor. Dolayısıyla bu rapora göre yaygın medyanın çocuklar söz konusu olduğunda yaptığı iki önemli hak ihlali var ve tıpkı kadınlara yapıldığı gibi; çocuklara da yoklarmış gibi davranılıyor, var olduklarında ise çoğunlukla olumsuz örnekler üzerinden hatırlanıyor (Alankuş, 2007: Önsöz). Medyanın yapısı düşünüldüğünde bunun çocuk için istenilen sonucu getirmeyeceği ortadadır. "Çocukluğun Yok Oluşu" adlı eserinde Neil Postman; Amerika'da 12-13 yaşlarındaki kız çocuklarının yüksek ücretli modeller arasında yer aldığını ve bu kızların tüm görsel iletişim araçlarındaki reklamlarda, bilmiş, cinsel çekiciliğe sahip yetişkinlerin kılığında giysiler içinde gayet rahat erotik bir hava içinde halka sunulduğunu belirtmiştir.

Yukarıdaki örnekte de görüldüğü gibi çocuk, medyada temsil edilirken, sıradan biri ise suçlu ya da mağdur olarak gösterilmekte ya da reklamlarda arzu nesnesi olarak hedonist bir anlayışla sunulmaktadır. Her iki durumda da medya, çocuğu hedef haline getirmektedir. Diğer insanların ona nasıl baktıkları, nasıl davrandıkları ruhunun yaralanmasına, benliğinin zarar görmesine neden olmaktadır. Zarar gören bir insanın tepkisi ise ya kendine bir şekilde zarar vermek ya da kendisini damgalayan, dışlayan, suçlayan, toplumun fertlerine zarar vermek biçiminde dışa vurmaktır.

Toplumun dışına atılan ve toplum tarafından sıra dışı olarak kabul edilen biri, bir süre sonra topluma zarar veren biri olarak karşımıza çıkabilir. Bu nedenle çocukları damgalamak, dışlamak, suçlamak yerine onları anlamak, kazanmak ve eğitmek ülkenin geleceği açısından çok önemlidir (Mora, 2007: 68).

Öncelikle çocuğun fiziksel ve ruhsal olarak korunmaya muhtaç doğası ile örtüşen modern dönemin çekirdek ailesi, post modernizm, küreselleşme, tüketim çağı ile erozyona uğramıştır. Bir bakıma kendi kendine ya da medya araçlarının himayesinde büyüyen yeni nesil çocukların bu haliyle 
kendi kendilerine yetebilmeleri, her şeyi bilmeleri beklenmektedir. Eleştirel Medya Okuryazarlığı Kapsamında Çocuk Odaklı Haber ve Programları daha iyi irdeleyebilmek için öncelikle bunlara aracılık eden medya araçlarını ve bunların muhtemel olumsuz etkilerini ölçmek gerekir.

\subsection{Televizyon}

Günümüz dünyasında hemen hemen her yaş grubundan insan televizyonun izleyicileri arasında yer almaktadır. Özellikle çocukların ekran karşısında geçirdiği sürenin çok yüksek olması, günümüzde medyayı aile ve yakın çevre gibi toplumsallaşma araçlarıyla rekabet eder duruma getirmiştir. Televizyonun yeni değerler kazanılmasında ya da davranışların biçimlendirilmesinde kesin bir etkisi vardır. Nitekim psikologlara göre, çocukların davranışları ile inançlarının televizyonda gördükleri ile biçimlendiği ve kendilerini gelecek yaşantılara hazırlarken de televizyonu araç olarak kullandıkları ifade edilmektedir. Televizyon izlemek çocukların iç dünyasında şiddeti, cinselliği, kültürel yozlaşmayı, bilinçsiz tüketimi, madde bağımlılı̆ı ve kötü alışkanlıkların özendirilmesini körükler.

Televizyonlarda yer alan programların analizi yapıldığında da çizgi filmlerin, reklamların, sinema filmlerinin ve haberlerin yine çocukların kişilik yapısı üzerinde olumsuz etkiler bıraktığı hatta küçük yaştaki bireylerin henüz tam anlamı ile bilmemelerinden dolayı, televizyon programlarının kurgusal olduğunu, politik söylemleri olduğunu, belli bir ideolojiye sahip olduğunu ve belli ticari kaygılara sahip olduğunu bilemezler, sorgulayamazlar. Televizyon karşısında geçirilen zaman bazı fizyolojik bozuklukları da beraberinde getirir. Ayrıca televizyon karşılıklı bir iletişimi öngörmediğinden pasif bir izleyici kitlesi meydana getirir. Televizyonun bir başka olumsuz etkisi de birçok özelliği bünyesinde barındırması nedeniyle kurumlar üzerinde olmaktadır. Örneğin sinema, tiyatro ve eğlence mekânları gibi yerlere alternatif gösterilmektedir.

\section{2. Radyo}

Radyo özellikle televizyona göre her mekânda ve her durumda rahatlıkla dinlenebilme, küçük ve taşınabilir olma ve her şeyden önemlisi de ucuz olma gibi üstünlüklere sahiptir. (RTÜK, 2007: 77) Bu nedenle de medya tüketicisinin çok rahat ulaşabileceği bir araçtır. Özellikle daha az bir teknolojik alt yapı ve yatırıma ihtiyaç duyması nedeniyle radyo diğer medya araçlarına nazaran daha hızı bir şekilde yaygınlaşmıştır. Radyo bu özelliği nedeniyle hem medya tüketicisi ve hem de radyoyu seçen medya sektör temsilcileri tarafından en ekonomik araç olarak da kullanılmaktadır.

Çocuklar tarafından çok talep görmemekle birlikte radyonun; dilin yanlış ve kötü kullanılması, küfür ve argo içerikli ifadelere yer verilmesi, müstehcen ifadeler veya imalar içeren konuşmalar yapılması, DJ olarak anılan radyo programı yapımcı ve sunucularının herhangi bir konuda, kişi, kurum ya da kuruluşlar hakkında hakaret ve aşağılama içeren ifadeler kullanılması gibi olumsuz yönleri yanında hayal dünyasına hitap etmesi nedeniyle de yanlış ve yalan sunumların önlenmesi pek mümkün olamamaktadır.

\subsection{Gazete ve Dergi}

İnsan, çevresinde ve dünyada olup bitenleri öğrenmek, öğrendiklerini veya düşündüklerini başkalarına duyurmak ihtiyacındadır. Gazetenin doğuşunda da hiç kuşkusuz insanoğlunun haber alma gereksinimi ve isteğinin büyük etkisi ve katkısı bulunmaktadır. Bir kitle iletişim aracı olarak gazetenin özelliklerine bakıldığında, gazete haber bilgi, yorum ve reklam içeren, genellikle düşük maliyetli kâğıt kullanılarak basılan ve dağıtımı yapılan bir medya aracıdır. Dergi ise gazete ile benzer özelliklere sahip olmakla birlikte daha az sıklıktaki periyotlarda yayın yapmasından dolayı içerik ve etki olarak gazeteden daha farklı hazırlanmaktadır. 
Gazete ve dergi; gerek içerik açııından ve gerekse görsel sunum açısından her istenildiği anda ve istenilen sürede ulaşılabilecek bir medya aracı olduğundan özellikle çocuklara yönelik haberlerin verilmesinde seçici davranılmamaktadır. Örneğin bir cinsel istismar haberi adeta çocukların beyinlerine en ince detayları ile işlenircesine yazııı ve renkli fotoğrafı ılarak sunulmaktadır. Bunu henüz okuma-yazma çağına girmiş bir küçük medya okuryazarı bu haliyle almakta ve saklamaktadır. Bu birikim zamanla çocuğun taşıyamayacağı bir yük haline gelerek başta kişilik bozuklukları olmak üzere minik bedenlerde sayısız kalıcı hasarlar bırakabilmektedir.

Çocukların yazııı basında temsil edilme düzeyi ve hangi sıklıkla yer aldığının tespitine yönelik olarak söylenecek ilk şey medyanın bu alanında yeterince temsil edilmedikleridir. Çocuklara yönelik olarak hazırlanan ve kabul gören birçok uluslararası sözleşme metinlerinden yola çıkılarak denilebilir ki; medyanın görevi her alanda çocuk haklarının korunması ve kullanılması konusundaki etik ve hukuki sorumlulukları gözeten, çocuk haklarına saygıı bir habercilik anlayışı ile çocukların toplumsal yaşama katılmalarını ve kendilerini ifade edebilme özgürlüklerini kullanabilecekleri uygun bir zemin yaratmak aynı zamanda da toplumsal farkındalık ve duyarlılık aşılamak olarak özetlemek mümkündür. (Sayılan ve Çevirgen, 2014: 97).

\section{4. İnternet}

Geçtiğimiz yüzyılın ikinci yarısında bilgisayar ve iletişim teknolojilerinin geliştirilip, bütünleştirilmesi ile sonuçlarının kestirilmesi çok güç etkiler doğuran bir dönem başlatmıştır. Günümüzde internetin eğitim, alışveriş, eğlence, iş ve iletişim gibi birçok alanda hizmet sunması hayatın ne kadar içinde olduğunun bir göstergesi sayılabilir. İnternetin yoğun kullanımı özellikle dijital çağda doğup büyüyen çocuklarda bir problem olarak karşımıza çıkmaktadır.

Internetin özellikle çocuklarda ve gençlerde daha yoğun olarak kullanılması ve tercih edilmesindeki en temel unsur; hızlı, modern, kolay ulaşılabilir, öğrenilebilir ve kolaylıkla istenildiğinde kişiselleştirilebilir olmasıdır. Bunun yanında internet erişim sayesinde bir tuşla ulaşılabilen çeşitli sitelerde; haber okuma, sohbet, e-posta, uzaktan eğitim, oyun, tanıtım gibi birçok sosyal içeriğe ulaşmak mümkün olabilmektedir. Bu konuda çeşitli projelerle medya okuryazarlığını geliştirme ve bireylerin iletişim araçlarının olumsuz etkilerinden mümkün olduğunca koruma çabası içinde olan RTÜK, çocukların daha bilinçli ve güvenli internet kullanıcıları olmalarına yardımcı olacak bazı önerilere internet sitesinde yer vermiştir.

\section{SONUÇ}

Haber verme ve halkı bilgilendirme basın yayın organlarının en temel görevleri arasında sayılır. Çünkü onların varlık nedenleri budur. Vatandaşın izleyici ya da okuyucu olarak onlara ilgi göstermesinin arkasında bu iddia vardır. Ancak öncelikle bu temel görevi sunan medya organlarının belki de sayı olarak en büyük ama yaş olarak en küçük olan tüketicilere yönelik olarak onları koruyucu ve kollayıcı ne gibi önlemler aldığını bilmek zorundayız.

Çocuk odaklı haber ve programlar hazırlanır ve sunulurken uluslararası arenada kabul görmüş çocuk haklarının varlığından haberdar mıyız? Hayır. Çünkü çocuk haklarının, hak literatüründe son derece önemli bir yeri bulunmasına ayrıca bu konuda ulusal politikalar çerçevesinde ve uluslararası işbirliği desteğinde gönüllülüğe dayalı başarılı çalışmalar yürütülmesine rağmen henüz istenilen boyuta gelmediğini söylemeliyiz (Onat ve Akço, 2007: 73).

Bunun yanında aşağıdaki soruların da cevabını bulmak bizim değerlendirmemizi kolaylaştıracaktır;

- $\quad$ Çocuklar medyada ne kadar temsil ediliyor?

- $\quad$ Çocuklar medyada nasıl temsil ediliyor? 
- $\quad$ Çocuklar haber içeriğinde hiyerarşik olarak hangi sırada veriliyor?

Ayrıca medyadaki sunumlardan dolayı çocuklara yönelik olarak hak ihlallerinin önlenebilmesi adına;

- Çocuk haklarına dair temel standartlar,

- Çocuk hakları alanında elde edilmek istenen gelişme,

- $\quad$ Çocuğun kitle iletişim araçlarından yararlanma hakkı, çıkmaktadır.

- Haberin konusu olan çocuğun istismar ve hak ihlalinden korunması başlıkları öne

Çocukların bu çerçevede iyi bir medya okuryazarı olmalarının yolu, anne ve babalarının da iyi birer medya okuryazarı olmasından geçtiğini söylemek yanlış olmaz. Aslında medya okuryazarlığının bireyleri medya tüketiminde daha eleştirel tüketiciler olmaları için bir takım düşünme becerilerine sahip olmaları gerektiği görüşüne dayandığı söylenebilir. (Kurt ve Kürüm, 2010:2)

Konuyu irdeleyen uzmanlarca şu soruların cevabının öncelikle verilmesi gereklidir:

- Medya okuryazarlığı nedir? Medya okuryazarlığı ne tür özellikler içermektedir?

- $\quad$ Eleştirel düşünme nedir? Eleştirel düşünen bireylerin özellikleri nelerdir?

vardır?

- Medya okuryazarlığı ve eleştirel düşünme arasında kavramsal çerçevede nasıl bir ilişki

Bu soruların doğru cevabını arayan biri aynı zamanda aşağıda sıralanmış özelliklere sahip bir medya okuryazarı özelliğini de kazanır.

- Medyayı doğru okuyarak yaşadığı çevreye duyarlı, ülkesinin problemlerini bilen, medyada gördüklerini aklın süzgecinden geçirecek düzeyde bilinç kazanır.

- Televizyon, video, sinema, reklâm, internet gibi ortamlardaki mesajlara ulaşarak bunları çözümleme, değerlendirme ve iletme yeteneği elde eder.

- $\quad$ Yazılı, görsel, işitsel medyaya yönelik eleştirel bakış açısı kazanır.

- Mesajların oluşturulmasına ve analizine dönük olarak cevap bulmaktan soru sorma sürecine doğru bir değişimi gündeme getirir.

- Bilinçli bir medya okuryazarı olur.

- Toplumsal yaşama daha aktif ve yapıcı şekilde katılır.

- Kamu ve özel yayıncılığın daha olumlu noktalara taşınması noktasında duyarlılık oluşturulmasına katkı sağlar

Çocukların pek çok konuyu genel anlamda medyadan öğrendiklerini ve medyada izlediklerini, duyduklarını, örnek aldıklarını biliyoruz. Bu konuda yapılan araştırmaların çoğu medyada gördükleri her şeyi hafızalarında tuttuklarını ve model aldıklarını göstermektedir. Dolayısıyla yazılı basın da dâhil olmak üzere, medyanın rolüne ilişkin ilk prensibi, özenli davranma yükümlülüğü olarak belirleyebiliriz. Ayrıca kitle iletişim araçları, çocukların toplumdaki rolünü pekiştirici yayın yapmalıdır.

Gelişen ve hızla değişen dünyada "elektronik oyuncaklarla kurgusal bir medya ortamında büyümek zorunda kalan" çocuklarımızın, sosyalleşmiş ve değer yargılarına sahip çıkan bireyler olması için herkesin üzerine düşeni yapması artık bir zorunluluktur. Tıpkı "yaşadığımız doğayı bizden sonrakilere koruyup bırakmak üzere aldığımız bir emanet olarak" gördüğümüz gibi çocuklarımızı da atalarımızdan aldığımız değerleri taşıyacak bireyler olarak görüp onları en iyi şekilde yetiştirmeli ve bir sonraki nesile aktarıımasını sağlamalıyız. 


\section{KAYNAKÇA}

ALANKUŞ, S. (2007) Neden Çocuk Odaklı Habercilik Kitabı, Çocuk Odakı Habercilik, Hak Haberciliği Dizisi, BİA - IPS İletişim Vakfı Yayınları, İstanbul.

AŞAR, E., (2014) Keşfedilen Çocuk, Iletişim Teknolojileriyle Yitip Giden Çocukluk ve Çocuk Kültürü, i\&D -iletişim ve Diplomasi- Dergisi, S. 2, T.C. Başbakanlık Basın-Yayın ve Enformasyon Genel Müdürlüğü, Ankara

AVŞAR, Z., (2014) Medya Okuryazarlığı, i\&D -illetişim ve Diplomasi- Dergisi, S.2, T.C. Başbakanlık Basın-Yayın ve Enformasyon Genel Müdürlüğü, Ankara.

BOSTANCI, N. (2014) Editörün Notu, i\&D -illetişim ve Diplomasi- Dergisi, S. 2, T.C. Başbakanlık BasınYayın ve Enformasyon Genel Müdürlüğü, Ankara.

DUMAN, A. (2000) Yetişkinler Eğitimi, Ütopya Yayınevi, Ankara.

iNAL, K. (2009), Medya Okuryazarlı̆̆ı Elkitabı, Ütopya Yayınevi, Ankara.

KURT, A.ve Kürüm, D. (2010) Medya Okuryazarlı̆̆ı ve Eleştirel Düşünme Arasındaki iliş̧ki: Kavramsal Bir Bakış, Mehmet Akif Ersoy Üniversitesi Sosyal Bilimler Enstitüsü Dergisi, 2 Bahar Sayısı, s. 2034.

MORA,N. (2014), Gençlerde Medya Bağımlılığı, i\&D -illetişim ve Diplomasi- Dergisi, S.2, T.C. Başbakanlık Basın-Yayın ve Enformasyon Genel Müdürlüğü, Ankara

MORA, N. (2007), İstanbul Üniversitesi İletişim Fakültesi 4. Çocuk ve İletişim Kongresi ve 4.Uluslararası Çocuk Filmleri ve Kongresi "Risk Altındaki Çocuklar" 22-24 Ekim 2007 tarihli Kongresinde sunulan "Medyada Çocuk Temsilleri ve Medya Okuryazarlı̆̆ı” adlı bildiri, İstanbul.

MORA, N. (2008), Medya Çalışmaları Medya Pedagojisi ve Küresel İletişim, Alt Kitap Yayıncılık, İstanbul.

ONAT, Y. ve Akço, S. (2007), Çocuk ve Habercilik, Neden Çocuk Odaklı Habercilik Kitabı, Çocuk Odaklı Habercilik, Hak Haberciliği Dizisi, Bi̇A - IPS İletişim Vakfı Yayınları, İstanbul. 
RTÜK, (2007), İlköğretim Medya Okuryazarlığı Dersi Öğretmen El Kitabı, Ankara

SAYILAN, G. ve Çevirgen, N. (2014), Yazılı Basında Çocuk Temsilleri: Bir Bekleme Salonu Olarak Çocukluk, I\&D -iletişim ve Diplomasi- Dergisi, S.2, T.C. Başbakanlık Basın-Yayın ve Enformasyon Gen.Müd., Ankara 
Adnan Menderes Üniversitesi, Sosyal Bilimler Enstitüsü Dergisi, Cilt: 1, Sayl: 2 (Sf. 70-79)

Adnan Menderes University, Journal of Institute of Social Sciences, Vol.: 1, Issue: 2 (pp. 70-79) 